\title{
Badanie stabilności termooksydacyjnej smarów plastycznych. Część 3 - Kompleksowe smary litowe
}

\begin{abstract}
W artykule przedstawiono wyniki badań laboratoryjnych odporności na utlenianie kompleksowych smarów litowych, wytworzonych na olejach bazowych, zaklasyfikowanych do trzech różnych grup według API, z zastosowaniem dodatków przeciwutleniających o różnej strukturze chemicznej. Badanie odporności na utlenianie prowadzono według klasycznej metody PN-C-04143, przeznaczonej do smarów plastycznych, oraz przy użyciu zmodyfikowanej metody PetroOXY.
\end{abstract}

Słowa kluczowe: smary, inhibitory utleniania, odporność na utlenianie.

\section{Determination of thermal-oxidation stability of lubricating greases.}

\section{Part 3 - Lithium-complex greases}

The article presents the results of laboratory tests of oxidation stability of lithium-complex greases, manufactured on base oils, classified into three different groups according to API, with the use of antioxidant additives with different chemical structure. The oxidation stability test was carried out according to the classic PN-C-04143 method, intended for lubricating greases, and using the modified PetroOXY method.

Key words: greases, antioxidants, oxidation stability.

\section{Wstęp}

Podczas eksploatacji środek smarowy, spełniając w układzie smarowania swoje podstawowe funkcje, narażony jest przede wszystkim na działanie wysokiej temperatury. Jedną z metod zapobiegania procesowi utleniania zarówno olejów bazowych, jak i środków smarowych jest dobór odpowiednich dodatków uszlachetniających. Stabilność termooksydacyjna smarów plastycznych może być modyfikowana poprzez wprowadzenie odpowiednich przeciwutleniaczy, których dobór zależy od rodzaju zagęszczacza smaru plastycznego oraz temperatury pracy smaru $[8,9]$.

Zadaniem inhibitorów utleniania (antyutleniaczy, przeciwutleniaczy) jest spowolnienie procesu utleniania oleju bazowego poprzez rozkład wodoronadtlenków, utworzonych w reakcji tlenu z węglowodorami, albo dezaktywację wolnych rodników nadtlenkowych. Smar plastyczny w czasie pracy jest w kontakcie $\mathrm{z}$ tlenem z powietrza, a wysoka temperatura i katalityczne właściwości metalu powierzchni tarcia stwarzają bardzo dobre warunki do utleniania oleju bazowego. Zachodzą w nim złożone reakcje autokatalitycznego utleniania, w wy- niku których powstają nowe substancje, takie jak: nadtlenki, alkohole, aldehydy, ketony, woda oraz kwasy. Produkty utleniania zwiększają lepkość oleju, powstają kwaśne zanieczyszczenia o właściwościach korozyjnych oraz osady takie jak żywice, laki i polimery [4].

Przedmiotem badań w niniejszej pracy były smary litowe kompleksowe, wytworzone na bazie dwóch rodzajów kwasów: 12-hydroksystearynowego i sebacynowego. Zagęszczacz powstaje dwuetapowo: w pierwszym etapie wytwarzania zagęszczacza smarów kompleksowych litowych powstaje sól litowa kwasu monokarboksylowego i sól litowa kwasu dikarboksylowego, natomiast $\mathrm{w}$ drugim etapie następuje wytworzenie mydła kompleksowego poprzez współkrystalizację obu tych komponentów. Smary kompleksowe litowe stanowią ok. 18\% wszystkich wytwarzanych na świecie smarów plastycznych [4]. Pozwalają one na podwyższenie temperatury użytkowania w stosunku do zwykłych smarów litowych o $50 \div 80^{\circ} \mathrm{C}$, przy jednoczesnym zachowaniu innych korzystnych właściwości. Podobnie jak zwykłe smary litowe mają 
one szerokie zastosowanie do smarowania skojarzeń trących w pojazdach samochodowych, jak też w różnych urządzeniach przemysłowych $[1,5,7]$.

C. Edinger w artykule [2] przedstawiła wyniki badań odporności na utlenianie 11 próbek smarów. Badania wykonano za pomocą aparatu RapidOxy (RSSOT - Rapid Small Scale Oxidation Test) $\mathrm{w}$ temperaturze $160^{\circ} \mathrm{C}$, zgodnie z ASTM D 525, oraz klasyczną dla smarów metodą ASTM D 942 (w temperaturze $99^{\circ} \mathrm{C}$, test 100 i 400 godzin). Porównanie uzyskanych wyników pozwoliło autorce na stwierdzenie, że istnieje dobra korelacja pomiędzy tymi metodami badawczymi. S.J. Nolan, na podstawie wyników badań przedstawionych w artykule [6] potwierdziła istnienie korelacji pomiędzy metodą RSSOT a tradycyjną metodą utleniania smarów ASTM D 942.

\section{Metodyki badawcze}

Badanie stabilności termooksydacyjnej kompleksowych smarów litowych prowadzono według dwóch metod badawczych: PN-C-04143:1956 Przetwory naftowe - Smary stałeBadanie odporności na utlenianie [10] oraz PN-EN 16091:2011 Ciekte przetwory naftowe - Paliwa i mieszaniny ze średnich destylatów naftowych i estrów metylowych kwasów tluszczo-

Tablica 1. Określone parametry metod badania stabilności termooksydacyjnej

\begin{tabular}{|l|c|c|c|}
\cline { 2 - 4 } \multicolumn{1}{c|}{} & Jednostka & PN-C-04143 & PN-EN 16091 \\
\hline Ciśnienie początkowe & $\mathrm{MPa}$ & 0,8 & 0,8 \\
\hline Temperatura & ${ }^{\circ} \mathrm{C}$ & 100 & 100 \\
\hline Ilość próbki w naczynku & $\mathrm{g}$ & 4 & 4 \\
\hline Liczba naczynek & szt. & 5 & - \\
\hline Czas & $\mathrm{h}$ & 100 & $\begin{array}{c}\text { czas [s] } \\
\text { Wynik badania }\end{array}$ \\
\hline
\end{tabular}

wych (FAME) - Oznaczanie stabilności oksydacyjnej metoda szybkiego utleniania w małej skali [11]. Oznaczenia te polegają na utlenianiu badanej próbki smaru w ściśle określonych warunkach ciśnienia, temperatury i czasu, które przedstawiono w tablicy 1.

\section{Surowce}

Surowce zastosowane do wytworzenia próbek kompleksowych smarów litowych:

- oleje bazowe grup I, IV i V według API - o właściwościach przedstawionych w tablicy 2 ,

- kompleksowy zagęszczacz litowy, na bazie kwasu 12-hydroksystearynowego i kwasu sebacynowego, inhibitory utleniania różnego typuprzedstawiono w tablicy 3 .

Tablica 2. Oznaczone właściwości fizykochemiczne olejów bazowych

\begin{tabular}{|l|c|c|c|c|}
\hline \multicolumn{1}{|c|}{ Właściwości olejów } & Jednostka & $\mathrm{S}$ & $\mathrm{H}$ & $\mathrm{P}$ \\
\hline Charakter oleju bazowego & - & parafinowy & naftenowy & polialfaolefinowy \\
\hline Grupa według API & - & $\mathrm{I}$ & $\mathrm{V}$ & $\mathrm{IV}$ \\
\hline Lepkość kinematyczna & & & & \\
- w temperaturze $40^{\circ} \mathrm{C}$ & $\mathrm{mm}^{2} / \mathrm{s}$ & 86,59 & 100,2 & 46,93 \\
- w temperaturze $100^{\circ} \mathrm{C}$ & & 10,24 & 8,823 & 7,891 \\
\hline Wskaźnik lepkości & - & 99 & 38 & 138 \\
\hline Barwa & - & 1,5 & 1 & 0,5 \\
\hline Temperatura płynięcia & ${ }^{\circ} \mathrm{C}$ & -12 & -28 & -57 \\
\hline Zawartość siarki & $\%(\mathrm{~m} / \mathrm{m})$ & 0,551 & 0,061 & - \\
\hline Liczba kwasowa & $\mathrm{mg} \mathrm{KOH} / \mathrm{g}$ & 0,015 & 0,010 & $<0,010$ \\
\hline Temperatura zapłonu & ${ }^{\circ} \mathrm{C}$ & 220 & 214 & 260 \\
\hline
\end{tabular}

\section{Sposób wytworzenia próbek smarów plastycznych}

Smary bazowe wytwarzano w reaktorze o pojemności $5 \mathrm{~kg}$ wyposażonym w mieszadło przeciwbieżne, następnie poddawano je homogenizacji w młynie korundowym typu Fryma, przy szczelinie $0,2 \mathrm{~mm}$. Skład i podstawowe właściwości próbek smarów bazowych KL-S0, KL-H0 i KL-P0 przedstawiono w tablicy 4.
Próbki kompleksowych smarów litowych zawierających inhibitory utleniania wytwarzano w reaktorze o pojemności $0,5 \mathrm{~kg}$. Odpowiednią ilość smaru bazowego podgrzewano, przy intensywnym mieszaniu, do temperatury $90 \div 100^{\circ} \mathrm{C}$ i w tej temperaturze wprowadzano inhibitory utleniania w ilościach 


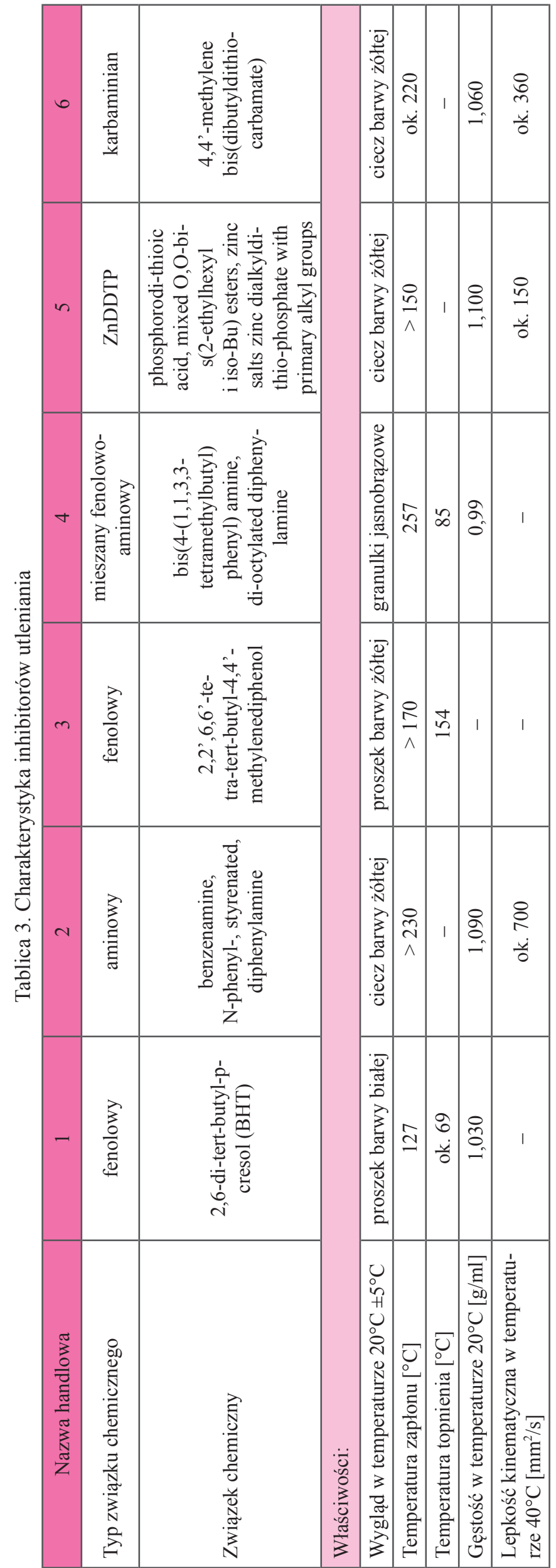

0,5\% $(\mathrm{m} / \mathrm{m})$. Smar schładzano dynamicznie (mieszając). Po ochłodzeniu próbki smarów poddawano homogenizacji w młynie korundowym typu Fryma, przy szczelinie 0,2 mm.

Tablica 4. Skład i właściwości smarów bazowych (nieinhibitowanych)

\begin{tabular}{|c|c|c|c|}
\hline 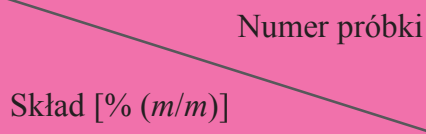 & KL-S0 & KL-H0 & KL-P0 \\
\hline Olej bazowy & $\mathrm{S}$ & $\mathrm{H}$ & $\mathrm{P}$ \\
\hline Sumaryczna ilość kwasów & 18,2 & 15,4 & 23,2 \\
\hline \multicolumn{4}{|l|}{ Właściwości: } \\
\hline $\begin{array}{l}\text { Penetracja w temperaturze } \\
25^{\circ} \mathrm{C} \text { po } 60 \text {-krotnym ugniata- } \\
\text { niu }[\mathrm{mm} / 10]\end{array}$ & 271 & 273 & 275 \\
\hline Temperatura kroplenia $\left[{ }^{\circ} \mathrm{C}\right]$ & 270 & 273 & 268 \\
\hline
\end{tabular}

\section{Badanie odporności na utlenianie}

Wytworzone smary kompleksowe litowe: bazowe i inhibitowane - przebadano w zakresie odporności na utlenianie według PN-C-04143 i zmodyfikowanej PN-EN 16091. Wyniki badań przedstawiono w tablicach 5 i 6 oraz na rysunkach 1 i 2 .

Na podstawie uzyskanych wyników badań odporności na utlenianie standardową metodą PN-C-04143 stwierdzono, że kompleksowy smar litowy wytworzony na bazie oleju polialfaolefinowego charakteryzował się najgorszą stabilnością termooksydacyjną spośród badanych nieinhibitowanych próbek smarów. W badaniu odporności na utlenianie tą metodą stwierdzono również, że:

- najwyższym wzrostem odporności na utlenianie w stosunku do smaru na bazie oleju parafinowego charakteryzowała się próbka KL-S1, zawierająca przeciwutleniacz typu fenolowego (1),

- żaden z zastosowanych w niniejszej pracy inhibitorów utleniania wprowadzony do smaru wytworzonego na bazie oleju naftenowego nie poprawia stabilności termooksydacyjnej tego smaru,

- najwyższym wzrostem odporności na utlenianie w stosunku do smaru na bazie oleju polialfaolefinowego charakteryzowały się próbki KL-P1 i KL-P2, zawierające przeciwutleniacz typu fenolowego (1) i aminowego (2),

- dodatek antyutleniacza typu karbaminian (6), zastosowany w próbkach kompleksowych smarów litowych, nie wykazał działania poprawiającego stabilność termooksydacyjną. Na podstawie uzyskanych wyników badań odporności na utlenianie zmodyfikowaną metodą PetroOXY stwierdzono, że kompleksowy smar litowy wytworzony na bazie oleju polialfaolefinowego charakteryzował się najlepszą stabilnością termooksydacyjną spośród badanych nieinhibitowanych próbek smarów. 
Tablica 5. Odporność na utlenianie według PN-C-04143 próbek kompleksowych smarów litowych

\begin{tabular}{|l|c|c|c|c|c|c|c|}
\cline { 3 - 8 } \multicolumn{2}{c|}{} & \multirow{2}{*}{$\begin{array}{c}\text { Smary } \\
\text { bazowe }\end{array}$} & \multicolumn{5}{c|}{ Smary inhibitowane antyutleniaczami } \\
\cline { 5 - 9 } & fenolowy & aminowy & fenolowy & $\begin{array}{c}\text { fenolowo- } \\
\text { aminowy }\end{array}$ & ZnDDTP & karbaminian \\
\hline Nr próbki & KL-S0 & KL-S1 & KL-S2 & KL-S3 & KL-S4 & KL-S5 & KL-S6 \\
\hline Spadek ciśnienia [MPa] & 0,594 & 0,019 & 0,035 & 0,054 & 0,054 & 0,037 & 0,577 \\
\hline Nr próbki & KL-H0 & KL-H1 & KL-H2 & KL-H3 & KL-H4 & KL-H5 & KL-H6 \\
\hline Spadek ciśnienia [MPa] & 0,560 & 0,558 & 0,539 & 0,560 & 0,555 & 0,523 & 0,506 \\
\hline Nr próbki & KL-P0 & KL-P1 & KL-P2 & KL-P3 & KL-P4 & KL-P5 & KL-P6 \\
\hline Spadek ciśnienia [MPa] & 0,625 & 0,015 & 0,015 & 0,017 & 0,040 & 0,033 & 0,570 \\
\hline
\end{tabular}

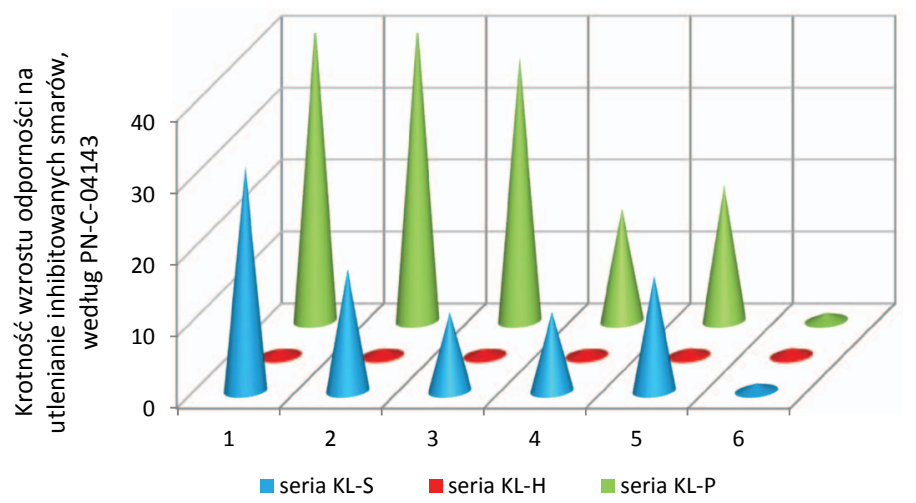

Rys. 1. Porównanie odporności na utlenianie według PN-C-04143 dla kompleksowych smarów litowych

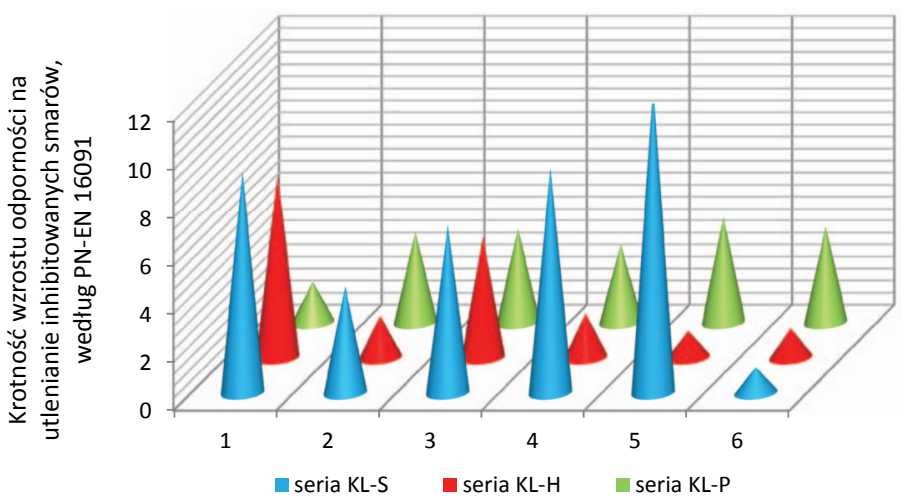

Rys. 2. Porównanie odporności na utlenianie według PN-EN 16091 dla kompleksowych smarów litowych

Tablica 6. Odporność na utlenianie według PN-EN 16091 próbek kompleksowych smarów litowych

\begin{tabular}{|l|c|c|c|c|c|c|c|}
\cline { 3 - 8 } \multicolumn{2}{c|}{} & \multirow{2}{*}{$\begin{array}{c}\text { Smary } \\
\text { bazowe }\end{array}$} & \multicolumn{6}{c|}{ Smary inhibitowane antyutleniaczami } \\
\cline { 5 - 9 } & fenolowy & aminowy & fenolowy & $\begin{array}{c}\text { fenolowo- } \\
\text { aminowy }\end{array}$ & ZnDDTP & karbaminian \\
\hline Nr próbki & KL-S0 & KL-S1 & KL-S2 & KL-S3 & KL-S4 & KL-S5 & KL-S6 \\
\hline Utlenianie [min] & 212,5 & 1954 & 940 & 1479 & 1984 & 2691 & 226 \\
\hline Nr próbki & KL-H0 & KL-H1 & KL-H2 & KL-H3 & KL-H4 & KL-H5 & KL-H6 \\
\hline Utlenianie [min] & 91,5 & 693,5 & 158 & 458 & 169 & 102 & 111 \\
\hline Nr próbki & KL-P0 & KL-P1 & KL-P2 & KL-P3 & KL-P4 & KL-P5 & KL-P6 \\
\hline Utlenianie [min] & 601 & 1016 & 2241 & 2334 & 1935 & 2642 & 2393 \\
\hline
\end{tabular}

Kompleksowy smar litowy wytworzony na bazie oleju o charakterze parafinowym wykazał przeszło dwukrotnie wyższą odporność na utlenianie niż kompleksowy smar litowy wytworzony na bazie oleju o charakterze naftenowym. W badaniu odporności na utlenianie tą metodą stwierdzono również, że:

- najwyższym wzrostem odporności na utlenianie w stosunku do smaru na bazie oleju parafinowego charakteryzowała się próbka KL-S5, zawierająca przeciwutleniacz typu ZnDTP (5),
- najwyższym wzrostem odporności na utlenianie w stosunku do smaru na bazie oleju naftenowego charakteryzowała się próbka KL-H1, zawierająca przeciwutleniacz typu fenolowego (1),

- najwyższym wzrostem odporności na utlenianie w stosunku do smaru na bazie oleju polialfaolefinowego charakteryzowała się próbka KL-P5, zawierająca przeciwutleniacz typu ditiofosforan cynku (5). 


\section{Próba ustalenia korelacji pomiędzy metodami}

Na podstawie wyników badań odporności na utlenianie kompleksowych smarów litowych dokonano próby wyznaczenia korelacji pomiędzy rezultatami otrzymanymi metodami PN-C-04143 i zmodyfikowaną PN-EN 16091, a tym samym pomiędzy samymi metodami. W tym celu sporządzono korelogram - wykres punktowy par $\{(x i, y i)\}$, gdzie: $x i$ i $y i$ to wyniki badania próbki ,i” dwiema metodami (rysunek 3). W przypadku otrzymania rozproszonego zbioru punktów, który nie przypomina kształtem wykresu znanego związku funkcyjnego, uznaje się, że pomiędzy cechami $X$ i $Y$ nie ma zależności. Odwrotnie, jeśli zdaje się, że obserwowany zbiór punktów układa się w charakterystyczny sposób, przyjmuje się istnienie zależności pomiędzy zmiennymi. Właściwość ta jest następnie potwierdzana obliczeniami przedstawionych poniżej wielkości statystycznych:

- współczynnik korelacji liniowej Pearsona $r$ - współczynnik określający poziom zależności liniowej między zmiennymi losowymi,

- współczynnik determinacji $R^{2}$, który jest miernikiem siły związku pomiędzy zmiennymi (podaje on, w jakiej części zmienność jednej cechy jest wyjaśniona przez drugą cechę). Otrzymany zbiór punktów nie przypomina kształtem wykresu znanego związku funkcyjnego, uznano zatem, że pomiędzy wynikami badań odporności na utlenianie 21 próbek smarów wykonanych w temperaturze $100^{\circ} \mathrm{C}$ według PN-C-04143 i PN-EN 16091 nie ma zależności.

Jednakże aby uzyskać liczbowe oszacowanie zależności, przy przyjęciu założenia korelacji liniowej, obliczono:

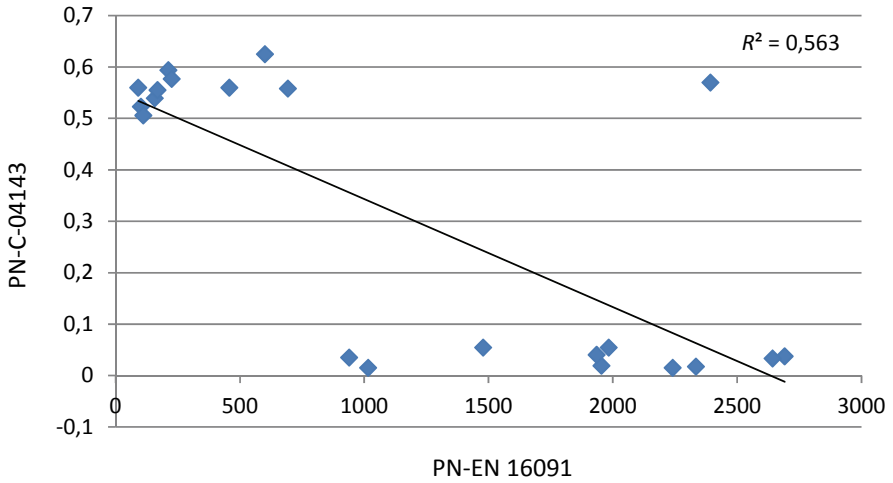

Rys. 3. Korelogram pomiędzy wynikami odporności na utlenianie smarów

- współczynnik determinacji na poziomie 0,56 - stopień dopasowania jest słaby,

- współczynnik korelacji $r$ na poziomie -0,75-dopasowanie jest zadowalające, jednak taki stopień korelacji w przypadku badań z zakresu nauk ścisłych jest uznawany za słaby. Do wyniku tego należy podejść z dużą ostrożnością ze względu na niepewność wyznaczonego współczynnika korelacji. Obliczony standardowymi metodami statystycznymi przedział ufności dla współczynnika korelacji na poziomie ufności 0,95 wynosi od $-1,0$ do $-0,51$. Tak duży zakres możliwych wartości współczynnika korelacji wynika z małej liczebności próby i dużego założonego poziomu ufności.

Podsumowując powyższe wyniki, stwierdzono, że korelacja pomiędzy metodami PN-C-04143 i PN-EN 16091 jest na tyle słaba, że uniemożliwia stosowanie tych metod wymiennie.

\section{Podsumowanie}

Stabilność termooksydacyjna kompleksowych smarów litowych może być modyfikowana poprzez wprowadzenie odpowiednich inhibitorów utleniania, których dobór będzie zależał od rodzaju zastosowanej bazy olejowej.
Korelacja pomiędzy metodami oznaczania stabilności termooksydacyjnej według norm PN-C-04143 i zmodyfikowanej PN-EN 16091 jest na tyle słaba, że uniemożliwia stosowanie tych metod wymiennie.

Prosimy cytować jako: Nafta-Gaz 2018, nr 1, s. 61-66, DOI: 10.18668/NG.2018.01.07

Artykuł nadesłano do Redakcji 15.11.2017 r. Zatwierdzono do druku 14.12.2017 r.

Artykuł powstał na podstawie pracy statutowej pt.: Badanie możliwości modyfikacji stabilności termooksydacyjnej smarów plastycznych - praca INiG - PIB na zlecenie MNiSW; nr zlecenia: 0094/TO/17, nr archiwalny: DK-4100-81/17.

\section{Literatura}

[1] Czarny R.: Smary plastyczne. Wydawnictwa Naukowo-Techniczne, Warszawa 2004.

[2] Edinger C.: New Test Method for Measuring the Oxidation Stability of Lubricating Greases - Rapid, Simple, Precise. Petro-Online.com (dostęp: 05.10.2017).

[3] Grease Production Survey Report 2008-2011, NLGI.

[4] Khamidullina L., Gussak A., Ivanova E., Trofimova O., Prokhorova P., Morzherin Yu.: Effect of Calix[n]Arene Derivatives on Oxidation Resistance of Plastic Lubricants. Chemistry and Technology of Fuels and Oils 2016, vol. 52, nr 5, s. 495-498.

[5] Mortier R.M., Fox M.F., Orszulik S.T.: Chemistry and Technology of Lubricants. Springer 2010, s. 411-432.

[6] Nolan S.J., Savin R.: The Evaluation of Oxidation Resistance of Lubricating Greases using the Rapid Small Scale Oxidation Test (RSSOT). ELGI Paper, Venice 2016.

[7] TOTAL: Poradnik. Rozdział XIX: Smary plastyczne; http:// 
www.total.com.pl/pro/B2B-produkty-dla-przemyslu/li-materialy-informacyjne/li-poradnik.html (dostęp: 05.10.2017).

[8] Trzaska E., Żółty M., Skibińska A.: Badanie stabilności termooksydacyjnej smarów plastycznych. Część 1 - Smary na oleju o charakterze parafinowym. Nafta-Gaz 2016, nr 11, s. 31-38, DOI: 10.18668/NG.2016.11.13.

[9] Trzaska E., Żółty M., Skibińska A.: Badanie stabilności termooksydacyjnej smarów plastycznych. Czesść 2 - Smary na oleju o charakterze naftenowym. Nafta-Gaz 2017, nr 1, s. 49-53, DOI: 10.18668/NG.2017.01.06.

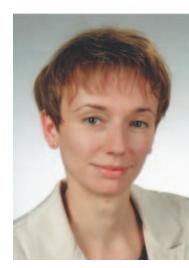

Mgr inż. Agnieszka SKIBIŃSKA

Asystent w Zakładzie Olejów, Środków Smarowych

i Asfaltów.

Instytut Nafty i Gazu - Państwowy Instytut Badawczy

ul. Lubicz $25 \mathrm{~A}$

31-503 Kraków

E-mail: agnieszka.skibinska@inig.pl

\section{Akty prawne i normatywne}

[10] PN-C-04143:1956 Przetwory naftowe - Smary state - Badanie odporności na utlenianie.

[11] PN-EN 16091:2011 Ciekte przetwory naftowe - Paliwa i mieszaniny ze średnich destylatów naftowych i estrów metylowych kwasów tluszczowych (FAME) - Oznaczanie stabilności oksydacyjnej metoda szybkiego utleniania w matej skali.

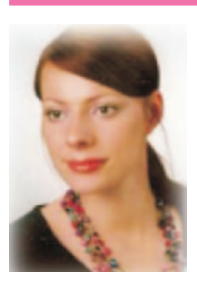

Mgr inż. Magdalena ŻÓŁTY

Specjalista badawczo-techniczny w Zakładzie Oceny Właściwości Eksploatacyjnych; kierownik Laboratorium Badań Właściwości Użytkowych.

Instytut Nafty i Gazu - Państwowy Instytut Badawczy ul. Lubicz 25 A, 31-503 Kraków

E-mail: magdalena.zolty@inig.pl

\section{OFERTA}

\section{ZAKŁAD OLEJÓW, ŚRODKÓW SMAROWYCH I ASFALTÓW}

Zakres działania:

- opracowanie i modyfikacja technologii wytwarzania:

» olejów podstawowych (bazowych),

» środków smarowych: olejów przemysłowych i smarów plastycznych,

» wosków naftowych (parafin i mikrowosków), wosków i kompozycji specjalnych oraz emulsji woskowych,

» dodatków stosowanych podczas wydobycia i transportu ropy naftowej i gazu ziemnego: inhibitorów korozji, inhibitorów parafin, inhibitorów hydratów, inhibitorów hydratów i korozji, deemulgatorów oraz inhibitorów oporów przepływu ropy naftowej,

» asfaltów drogowych i przemysłowych,

» olejów technologicznych do obróbki metali: emulgujących i nieemulgujących,

» niskokrzepnących płynów do chłodnic samochodowych i spryskiwaczy samochodowych;

- $\quad$ specjalistyczne badania oraz ocena właściwości fizykochemicznych i użytkowych:

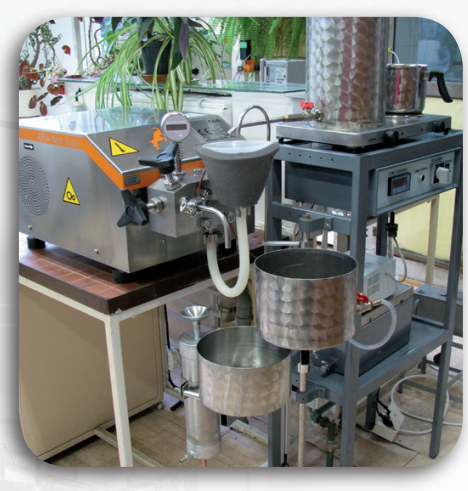

» środków smarowych, smarów plastycznych i olejów przemysłowych, silnikowych,

» wosków naftowych, wosków specjalnych oraz kompozycji i emulsji woskowych,

» asfaltów drogowych przemysłowych oraz emulsji asfaltowych, roztworów i mas asfaltowych oraz innych specyfików asfaltowych;

- $\quad$ opracowywanie zagadnień związanych z gospodarką olejami odpadowymi i odpadami rafineryjnymi;

- $\quad$ sporządzanie ekobilansów procesów technologicznych metodą Oceny Cyklu Życia (LCA).

Kierownik: mgr inż. Stefan Ptak

Adres: ul. Łukasiewicza 1, 31-429 Kraków

Telefon: 126177574

Faks: 1261774 30, 126177522

E-mail: stefan.ptak@inig.pl 